\title{
The challenge and need for Energy \& Environmental Science
}

\author{
DOI: $10.1039 / b 810864 c$
}

"Energy is the single most important challenge facing humanity today."

Nobel Laureate Rick Smalley, April 2004, Testimony to U.S. Senate

Energy issues - encompassing generation costs, security of supply, and the environmental consequences of waste streams - are foremost among the world's geopolitical concerns. The fossil fuels-coal, natural gas, and petroleum-supply approximately $85 \%$ of all the energy consumed today by the world's industrialized nations. Energy is vitally needed to bring electric power to the one quarter of the world's population that currently lacks it, to support the industrialization of developing nations to bring billions out of poverty, and to sustain economic growth and productivity in developed countries. Ensuring security of the domestic energy supply is currently a major national security issue for many countries. In addition, climate change considerations are receiving unprecedented levels of importance in affecting regional, national and global energy policy decisions.

"We must change the trajectories of our energy usage and energy sources. World peace, economic development for much of the world, continuing prosperity for the developed countries and a stable climate require us to do so. To create and analyze options, and to educate and inform people about the work ahead, scientists and engineers are critical...It is our privilege and our responsibility to rise to these energy challenges."

Ralph Cicerone, President, U.S. National Academy of Sciences, Address to U.S. National Academy of Sciences, April 28, 2008
Yet the historical approach to addressing increased energy supply needs, fossil fuel consumption coupled with energy conservation, will not be scaleable to meet future energy demands. U.N. projections indicate that meeting global energy demand in a sustainable fashion by the year 2050 will require not only increased energy efficiency and entirely new methods of utilizing existing carbon-based fuels, but will additionally require a very significant fraction of the U.S. and global energy supply to be in the form of carbon-free power.

Where will this energy come from, and how can it be produced and utilized in an environmentally sustainable fashion?

The answers are not presently known, but several aspects are clear. First, the most important energy problems hinge upon fundamental advances in science and technology. Second, ultimately we as a society will have to replace fossil fuels for much of our energy needs, yet at the present time we are not positioned to do so, and hence continued shortterm reliance on fossil fuels appears inevitable. The most fruitful research directions will thus be ones that embrace these realities.

Energy research can be broadly categorized into three themes: increased energy efficiency and energy utilization (batteries, fuel cells, LED-based lighting, etc.); alternative energy (solar, wind, biofuels, etc.), and conventional energy (fossil energy with or without carbon capture and storage, and nuclear power). In response to a clear and pressing need, Energy \& Environmental Science is a new journal that is uniquely chartered to act as a central location for publication and dissemination of key results and advances in all of these areas.

Enthusiastically supported by international Editorial and Advisory Boards of the highest caliber, Energy \& Environmental Science welcomes contributions that range from new insights into photovoltaics to the synthesis of important new hydrogen storage materials; from new developments in hydrogen production from biomass to global climate change; from artificial photosynthesis to fuel cells; and from environmental catalysis to nanostructured materials for energy applications. In addition, position papers and perspectives from key thought leaders on the economic, social, political and environmental impacts of energy use, of changes in the energy mix, and of changes in the value proposition offered by new and different energy efficiencies and energy services will also be a key part of the journal.

Progress in transitioning to a globally scalable and sustainable energy system is a world-wide problem and demands contributions from scientists, engineers, economists, policy makers, and decision makers around the world. Rapid progress on this urgent issue depends on the integration of perspectives in all of these areas, which is the underlying and unique charter of Energy \& Environmental Science as a leading, interdisciplinary journal.

\section{Professor Nathan Lewis}

George L. Argyros Professor of Chemistry, California Institute of Technology

Editor-in-Chief, Energy \& Environmental Science

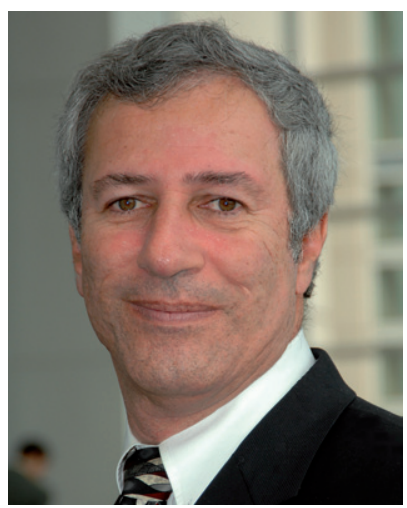




\section{Editorial information}

Welcome to the first issue of Energy \& Environmental Science. I lead the Editorial Team in Cambridge, taking care of the day-to-day running of the journal. The Editorial Team ensures a peer-review process that is fair, high quality, rigorous, and very efficient. We recognise the importance to many authors of rapid publication, and as shown by the articles published in this issue we are already destined to become the quickest journal in the field.

Above all, we are committed to ensuring that Energy \& Environmental Science meets the requirements and aspirations of the communities it serves, and becomes essential reading for all those working in the vitally important areas of energy and related environmental research.

We sincerely hope that you will enjoy reading this exciting new journal and will submit some of your best work for publication in it. Some important Editorial information is included below.

We welcome your feedback and suggestions at any time-please contact ees@rsc.org with your views and ideas.

\section{Philip Earis}

Editor, Energy \& Environmental Science

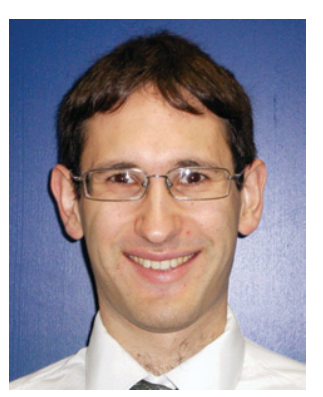

\section{Article types}

Energy \& Environmental Science publishes a lively mix of article types, including original research Papers and Communications, "Perspective" feature review articles, Minireviews, and important Opinion pieces from leaders in the field. All articles submitted to Energy \& Environmental Science are subject to rigorous peer-review by international expert referees. All accepted articles are published online as fully-citeable Advance Articles as soon as they are ready.

\section{Free online access}

Energy \& Environmental Science will be published in monthly issues. The journal is published by the Royal Society of Chemistry - a leading learned society publisher, with a proud history of publishing excellence and innovation in electronic developments.

To maximise the visibility of work published, the current issue of Energy \& Environmental Science-plus any Advance Articles - will be freely available to all on our website (www.rsc.org/ees).

In addition, the entire 2008 and 2009 content will be freely available following a simple registration process. Access is managed by institution and IP address. Make sure your organisation takes advantage of this by registering at www.rsc.org/ees_registration.

\section{Browsing and alerting services}

The Energy \& Environmental Science homepage contains the contents list for the current issue, delivering the content you want to see as soon as you arrive at the site. Graphical abstracts are included as standard, allowing you to easily browse content. A prominent and easy-to-use search box also makes finding published research much more intuitive.

RSS feeds for Energy \& Environmental Science also include graphical abstracts, enabling at-a-glance identification of relevant articles. To get the latest articles delivered straight to your screen, sign up at www.rsc.org/rss - or you can sign up for e-mail contents alerts at www.rsc.org/ ej_alert.

\section{Submission details}

We believe life should be as simple as possible for authors at the submission stage. We are happy to receive submissions (in almost any electronic format), either as an email attachment to ees@ rsc.org, or through the ReSourCe web submissions service (www.rsc.org/ resource).

Our full author guidelines, including preferred referencing style, are available on the Energy \& Environmental Science website at www.rsc.org/ees. Our journal templates (available from the website) are designed to assist submission in a format similar to the journal layout. However, we are willing to consider articles in almost any reasonable format and layout.

Of course, all published articles are put into a standardised format by our professional technical staff.

\section{Colour policy}

We are happy to print figures in colour, free of charge, where the use of colour enhances the scientific understanding of the figure. In addition, for the online version of the journals, colour is always provided at no cost in both the pdf and html versions.

\section{Citing}

When you cite Energy \& Environmental Science articles in future manuscripts please note that the correct journal abbreviation is Energy Environ. Sci. 